\title{
Endodontic management of a maxillary first molar with two roots and iatrogenic perforation diagnosed with the aid of cone beam computed tomography
}

\author{
Neha Arora ${ }^{1 *}$, Hemanth Vagarali ${ }^{2}$, Madhu Pujar ${ }^{3}$, Veerendra M Uppin ${ }^{4}$, Nikita Bhosale ${ }^{5}$ \\ ${ }^{1,5}$ PG Student, ${ }^{2,4}$ Professor, ${ }^{3}$ Professor and HOD, Dept. of Conservative Dentistry and Endodontics, Maratha Manadal Dental College, \\ Belagavi, Karnataka, India
}

*Corresponding Author: Neha Arora

Email: neha13nov@gmail.com

\begin{abstract}
Management of maxillary first molar with aberrant anatomy is a endodontic challenge, careful observation of periapical radiograph is a must to ensure clinical success. CBCT should be used for knowing canal architecture properly and to avoid any perforations. In this case report endodontic therapy of left maxillary first molar was done after careful analysis of CBCT images and perforation repair was done using MTA.
\end{abstract}

Keywords: Maxillary molar, Two roots, Vertuccis type V, Perforation repair.

\section{Introduction}

The success of endodontic therapy largely depends on thorough knowledge of root canal system. If the clinician doesn't have thorough knowledge of anatomical variation it may lead to endodontic failure due to missed canal. ${ }^{1}$ Maxillary first molar most commonly has three roots and three or four canals. Variations do exist and many studies have been published with respect to number of roots and root canals but very few cases have been reported with less number of roots and root canals. The significance as well as incidence of anatomical variations has been documented very well. ${ }^{2,3}$

Iatrogenic perforation can occur due to disorientation of operator while trying to locate canal orifices. Repair of a perforation should be done as soon as possible so as to seal the perforation site immediately and effectively to prevent microbial contamination and periodontal attachment apparatus injury. The two most important factors that play major role in deciding the treatment and prognosis of the tooth are time lapse between exposure and repair and the location of perforation. ${ }^{4,5}$

The present case report documents the successful endodontic management of a maxillary first molar with two roots where buccal root had Vertucci's Type V canal configuration and iatrogenic perforation repair with MTA.

\section{Case Report}

A 32 year-old female patient presented with chief complaint of pain in left maxillary posterior region for past several days. The patient started experiencing pain 2 months back but reported to the dentist only when it had increased in intensity and was not relieved by medication. The pain was continuous and moderate in intensity, which aggravated on consuming hot and cold foodstuffs. Medical history was noncontributory. On clinical examination, left maxillary first molar was found to be carious. Tooth \#26 seemed to be deeply carious and showed no presence of pain on palpation or tenderness on percussion. Periodontal probing was within physiologic limits around \# 26. In tooth \#26, tooth sensibility testing with electric pulp tester elicited an early response while on thermal pulp testing with heated Gutta-percha, a lingering intense response was seen. Preoperative radiograph (Fig. 1) of tooth \#26 showed a disto-occlusal radiolucency in the crown approaching the pulp space with no widening of the periodontal ligament space and a normal periapical tissue. There seemed to be present only two roots, but the canal architecture was difficult to comprehend. Based on all clinical and radiographic findings, a diagnosis of symptomatic irreversible pulpitis was established in tooth \#26. Endodontic treatment was hence planned in tooth \#26.

Treatment was initiated after administering 2\% lignocaine with 1:80,000 epinephrine to achieve local anesthesia. Under complete rubber dam isolation, in tooth \#26; access cavity was prepared. Clinical examination of pulp chamber floor revealed the existence of only two canal orifices. One orifice was located toward the buccal and was larger (Fig. 2a) when compared to the typically found buccal orifice in a maxillary first molar. The second orifice was located towards the palatal side (Fig. 2b).Working length was determined using 15 no. k files (Fig. 3). Cleaning and shaping done with protaper file system using crown down technique under copious irrigation with 3\% NaOCL and 17\% EDTA and master cone iopa was taken (Fig. 4). However in a quest of finding third canal, access cavity was extended further in mesial direction that resulted in perforation of root (Fig. 5). Since the buccal root was quite bulbous, and the canal outline was not very clear, need was felt to use CBCT scan to ascertain the presence of any variation in the canal configuration.

CBCT scanning provided valuable information with respect to canal configuration. In the $\mathrm{CBCT}$ images, 2 rooted molar can be seen in sagittal section (Fig. 6a). Type V (1-2) canal configuration (vertucci's classification) was observed in the buccal root while Type I canal configuration was observed in the palatal root of tooth \#26 in the axial sections (Fig. 6b).

On next visit, taking into account the available information, other canal was negotiated in the buccal root (Fig. 7) Working length was determined using 15 no. kfile. Cleaning and shaping done using rotary ProTaper nickeltitanium instruments (Dentsply Maillefer) using crown down 
technique (Dentsply, Maillefer, Switzerland) under copious irrigation with $3 \% \mathrm{NaOCl}$ and $17 \%$ EDTA. Later perforation repair was done using MTA after blocking the canals using Teflon and GP, the perforation site was present on mesial surface just below the alveolar crest. Following perforation repair, the canals were properly dried using paper points, calcium hydroxide (RC CAL) intracanal dressing was given and access cavity was provisionally sealed with cavit. On recall appointment at 1 -week, the patient was completely asymptomatic and root canals were obturated with Guttapercha (Dentsply, Maillefer, Switzerland) using cold lateral compaction technique and $\mathrm{AH}$ Plus resin as a sealer (Dentsply, De Trey, Germany). The access cavity was permanently restored with miracle mix (Fig. 8). Later a full coverage crown was given. The patient was recalled after 6 months for follow-up. At recall appointment, the patient continued to be asymptomatic, and radiograph showed a sound periapex (Fig. 9).

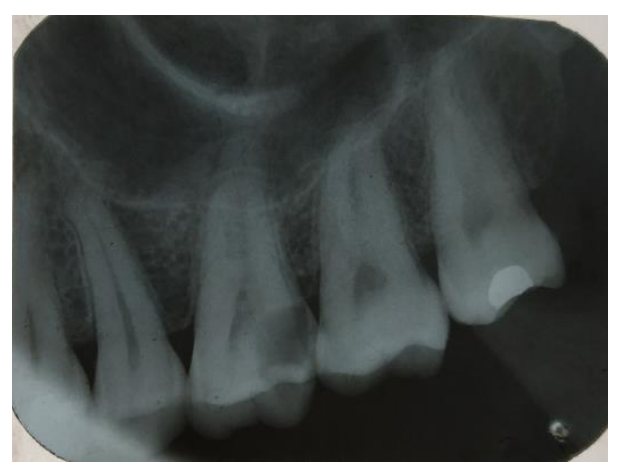

Fig. 1

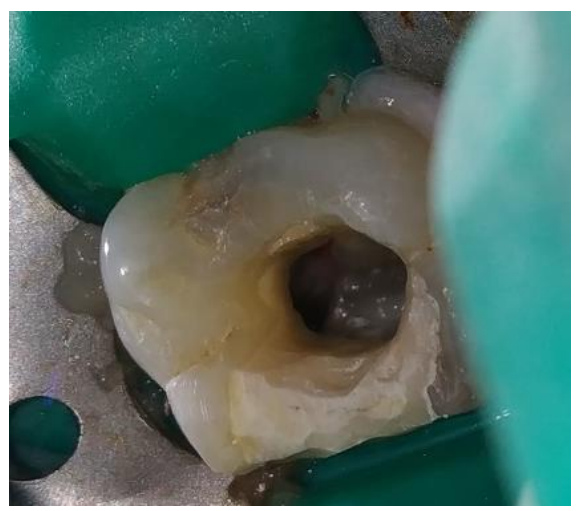

Fig. 2a

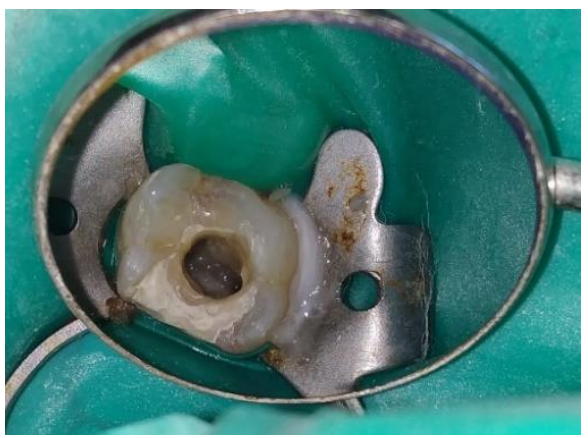

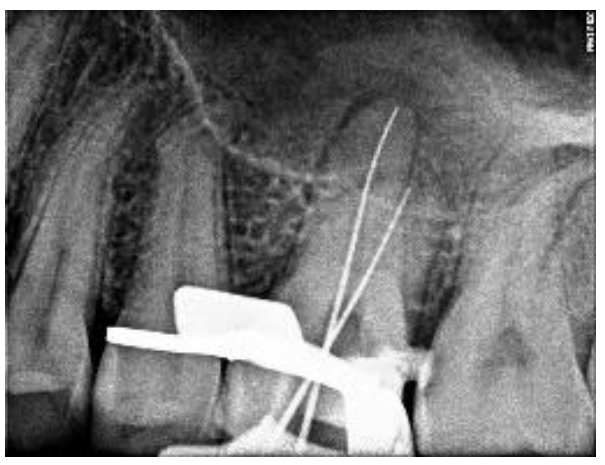

Fig. 3

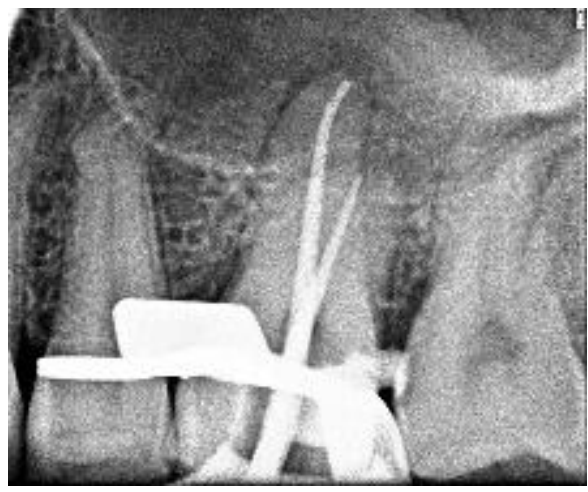

Fig. 4

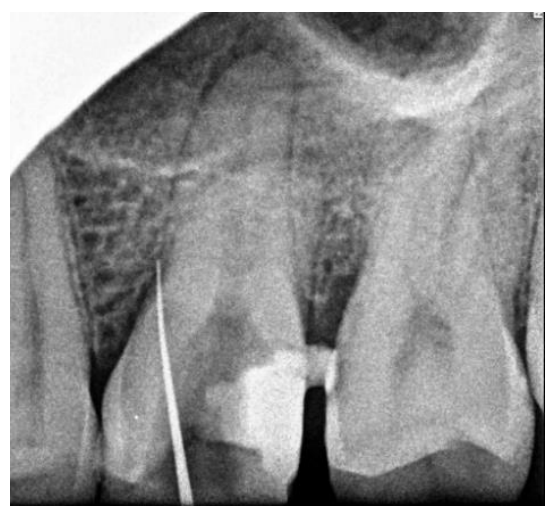

Fig. 5

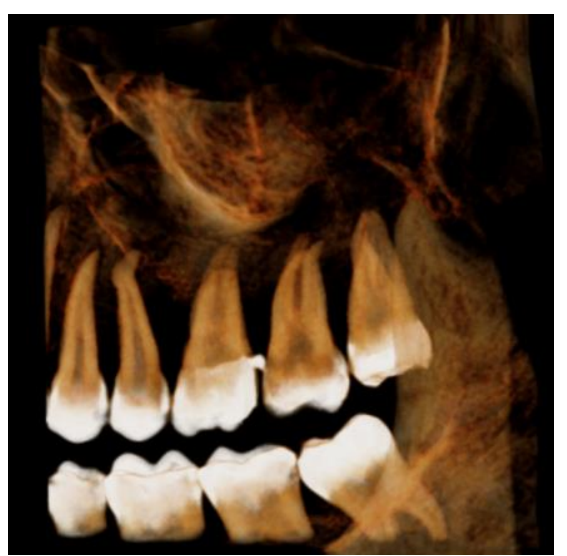

Fig. 6a

Fig. 2b 

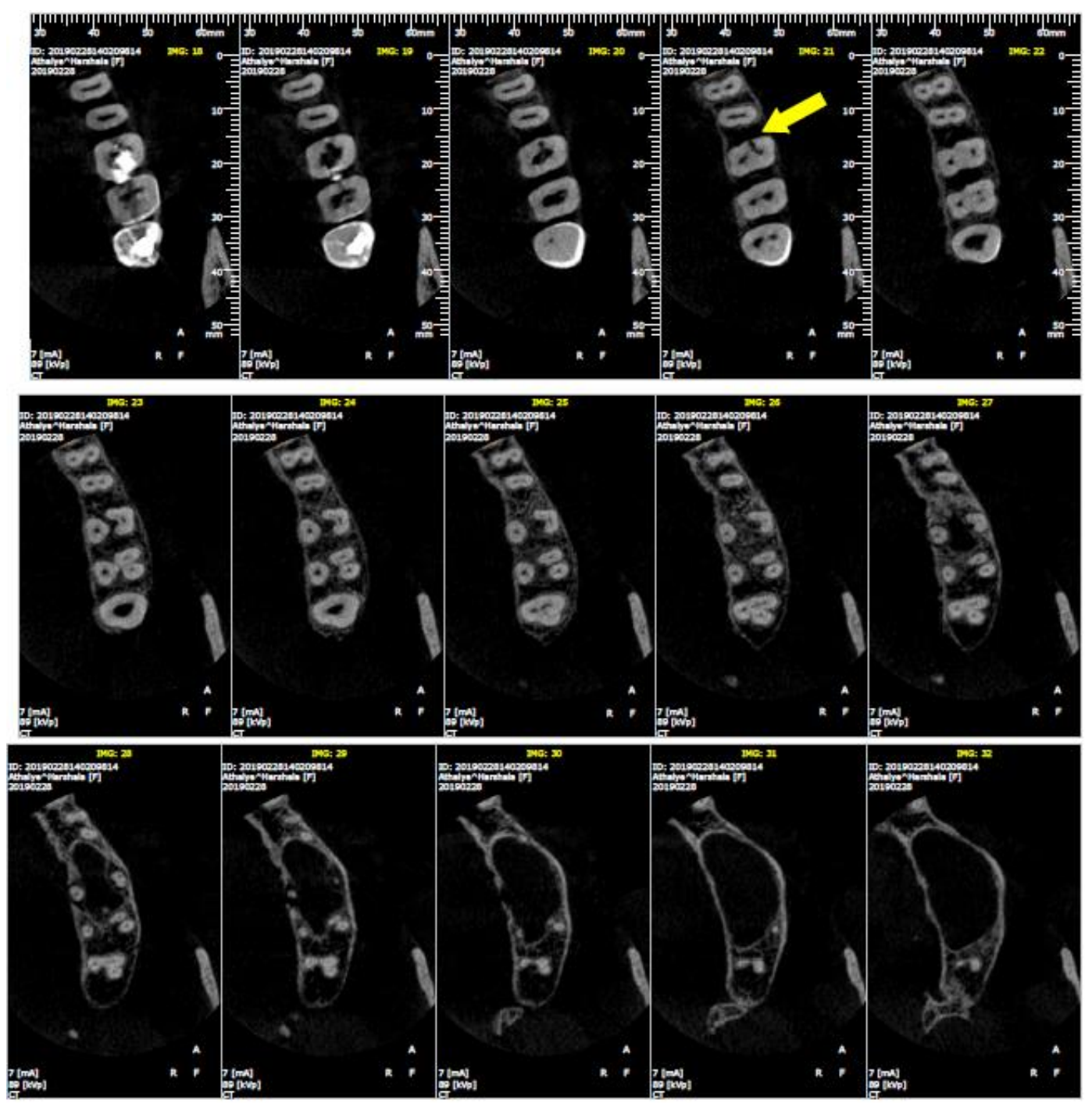

Fig. 6b

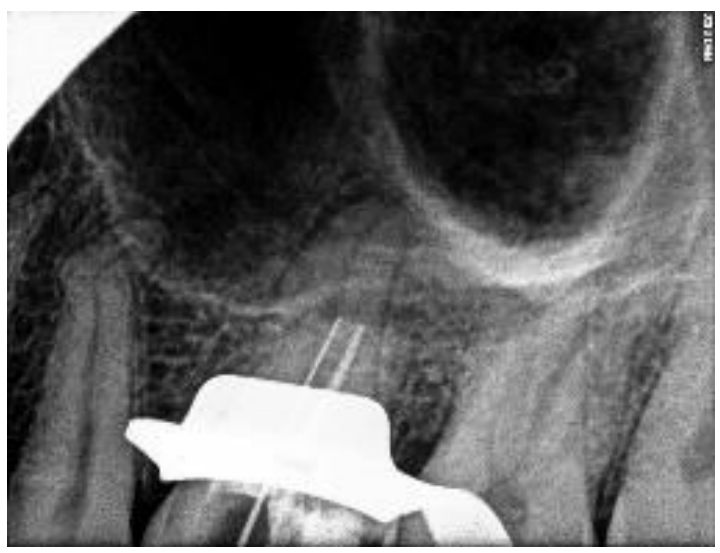

Fig. 7

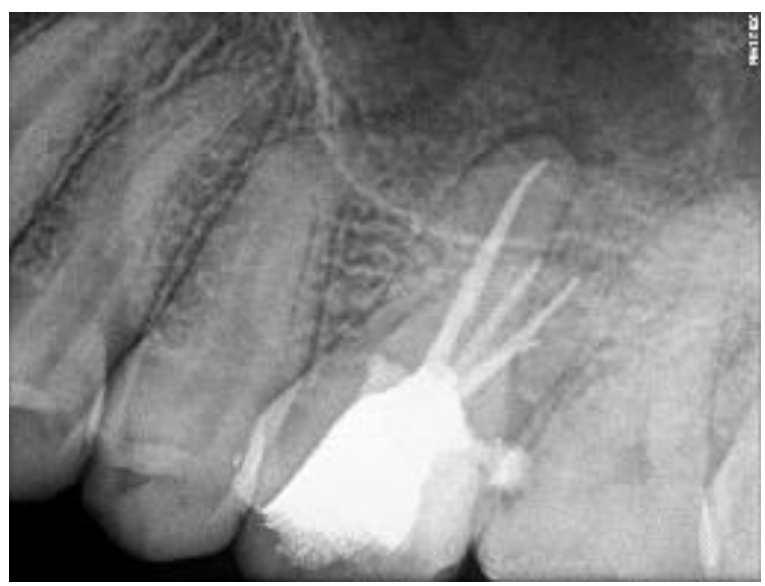

Fig. 8 


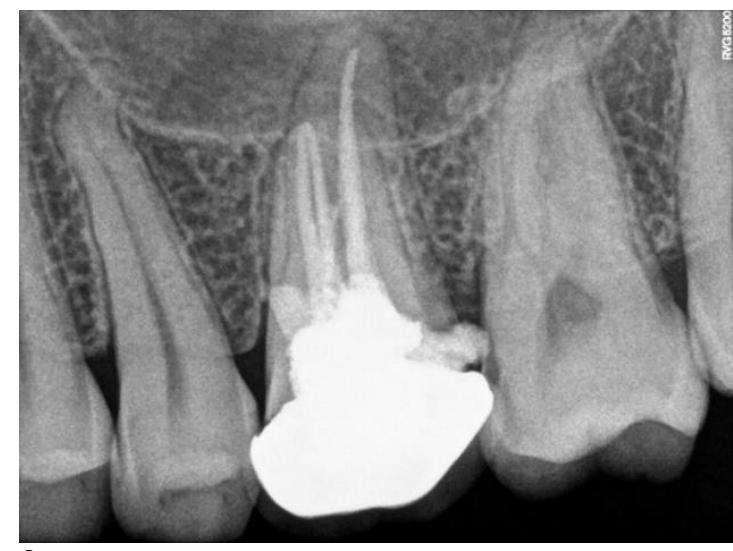

Fig. 9

\section{Discussion}

In this case report detailed analysis of the root canal morphology of maxillary first molar was done using CBCT. The main advantages of $\mathrm{CT}$ are that it is nondestructive and allows 3D reconstruction and visualization of the external and internal anatomy of the teeth. ${ }^{7}$ The primary advantages of CBCT are significantly lower effective radiation dose, short exposure time (2-5 seconds), less expensive than conventional CT, and highly accurate. Furthermore, CBCT measurements are geometrically accurate, owing to the fact that the CBCT voxels (3D pixels containing data) are isotropic. $^{8,9}$

Maxillary first molars usually has three roots (96.2\%) and three to four root canals (98.32). ${ }^{10,11}$ The two-rooted form of the maxillary first molar is rarely reported. Several previous studies in vitro, have shown that the incidence of maxillary first molar with only two roots varies from 0 to $6.3 \% .{ }^{12-14}$ To date, there is only one report in the literature of one single buccal root and one single palatal root, which should be emphasized to avoid treatment errors. ${ }^{1}$ In the present report, the patient's CBCT images showed that the two roots were separated. One was the buccal root and the other was the palatal root. The root canals from buccal orifice had vertucci type $\mathrm{V}$ configuration and root canal from palatal orifice had vertucci type I configuration, opened from the same chamber and had their own apex.

When there is presence of only one buccal root, two possibilities could be that there is only one buccal root or that two buccal roots have fused into a large root. This might have happened in embryologic stage, when the epithelium is not developed completely, the inadequate Hertwig sheath may have cause the fusion of roots. ${ }^{15,16}$

Iatrogenic perforation can occur if the operator becomes disorientated while trying to locate canal orifices. Perforation repair can be technically challenging. Management of iatrogenic perforation is dependent on several factors. ${ }^{17}$

\section{Time}

Perforation should be sealed as soon as possible to prevent contamination by bacteria and microleakage.

\section{Level}

As we move apically from crestal bone, the prognosis increases as there is high risk of microleakage when perforation is present at level of crestal bone. Guarded prognosis might be there due to direct communication with oral cavity through periodontal tissues.

\section{Size}

Larger the size, more attachment loss will be there.

Calcium silicate materials such as MTA and Biodentin have excellent biocompatibility and are able to induce calciumphosphate precipitation at the periodontal ligament interface allowing bony healing. Also these materials have superior sealing ability. ${ }^{18-20}$

\section{Conclusion}

Variations exist in root number, morphology, and canal morphology of maxillary first molar. The clinician should be aware of this. This will prevent any treatment error and will increase the success of root canal therapy. CBCT is an efficient method of studying root canal systems and should be instituted wherever necessary.

\section{Source of Funding}

None.

\section{Conflict of Interest}

None.

\section{References}

1. Gopikrishna V, Bhargavi N, Kandaswamy D. Endodontic management of a maxillary first molar with a single root and a single canal diagnosed with the aid of spiral CT: A case report. J Endod. 2006;32(7):687-91

2. Christie WH, Peikoff MD, Fogel HM. Maxillary molars with two palatal roots: a retrospective clinical study. J Endod. 1991;17:80-4

3. Jung IY, Seo MA, Fouad AF. Apical anatomy in mesial and mesiobuccal roots of permanent first molars. J Endod. 2005;31:364-8.

4. Roda RS. Root perforation repair: Surgical and nonsurgical management. Pract Proced Aesthet Dent. 2001;13:467-72.

5. Biswas M, Mazumdar D, Neyogi A. Non Surgical perforation repair by mineral trioxide aggregate using dental operating microscope. J Conserv Dent. 2011;14:83-5.

6. Davies A, Mannocci F, Mitchell P, Andiappan M, Patel S.The detection of periapical pathoses in root filled teeth using single and parallax periapical radiographs versus cone beam computed tomography- aclinical study. Int Endod J. 2015;48(6):582-92.

7. Gambarini G, Piasecki L, Miccoli G, Gaimari G, Nardo DD, Testarelli L. Cone-beam computed tomography in the assessment of periapical lesions in endodontically treated teeth. Eur J Dent. 2018;12(1):136-43.

8. AAE, AAOMR, editors. AAE and AAOMR joint position statement - use of cone-beam-computed tomography in endodontics 2010.

9. Dinsbach N. Benefits of preoperative cone beam computed tomography for root canal therapy in posterior teeth. Gen Dent. 2018;66(1):6-8.

10. Cleghorn BM, Christie WH, Dong CC. Root and root canal morphology of the human permanent maxillary first molar: a literature review. J Endod. 2006;32:813-21. 
11. Shalabi RM, Omer OE, Glennon J, Jennings M, Claffey NM. Root canal anatomy of maxillary first and second permanent molars. Int Endod J. 2000;33:405-14.

12. Thomas RP, Moule AJ, Bryant R. Root canal morphology of maxillary permanent first molar teeth at various ages. Int Endod J. 1993;26:257-26.

13. Paksefat S, Rahimi S. Root canal treatment of a two-rooted Cshaped maxillary first molar: a case report. Iran Endod J. 2014;9(4):301-3.

14. Fava LR. Root canal treatment in an unusual maxillary first molar: A case report. Int Endod J. 2001;34:649-53.

15. Yilmaz Z, Tuncel B, Serper A, Calt S. C-shaped root canal in a maxillary first molar: A case report. Int Endod $J$. 2006;39:162-6.

16. Sharma S, Mittal M, Passi D, Grover S. Management of a maxillary first molar having atypical anatomy of two roots diagnosed using cone beam computed tomography. J Conserv Dent. 2015;18:342-5.
17. Fuss Z, Trope M. Root perforations: Classification and treatment choices based on prognostic factors. Endod Dent Traumatol. 1996;2(6):255-64.

18. Parirokh M, Torabinejad M. Mineral trioxide aggregate: a comprehensive literature review--Part I: chemical, physical, and antibacterial properties. J Endod. 2010;36(1):16-27.

19. Torabinejad M, Parirokh M, Dummer PMH. Mineral trioxide aggregate and other bioactive endodontic cements: an updated overview - part II: other clinical applications and complications. Int Endod J. 2018;51(3):284-317.

20. Baroudi K, Samir S. Sealing ability of MTA used in perforation repair of permanent teeth; Literature review. Open Dent J. 2016;10:278-86.

How to cite this article: Arora N, Vagarali H, Pujar M, Uppin VM, Bhosale N. Endodontic management of a maxillary first molar with two roots and iatrogenic perforation diagnosed with the aid of cone beam computed tomography. Int J Oral Health Dent 2020;6(1):50-4. 